Relations industrielles

Industrial Relations

\title{
A History of American Labor, by Joseph G. Rayback, The MacMillan Company, New York 1959, Brett-MacMillan Ltd., 132 Water Street South Galt, Ont. \$6.00
}

\section{Gérard Dion}

Volume 14, numéro 4, octobre 1959

URI : https://id.erudit.org/iderudit/1022146ar

DOI : https://doi.org/10.7202/1022146ar

Aller au sommaire du numéro

Éditeur(s)

Département des relations industrielles de l’Université Laval

ISSN

0034-379X (imprimé)

1703-8138 (numérique)

Découvrir la revue

Citer ce compte rendu

Dion, G. (1959). Compte rendu de [A History of American Labor, by Joseph G. Rayback, The MacMillan Company, New York 1959, Brett-MacMillan Ltd., 132 Water Street South Galt, Ont. \$6.00]. Relations industrielles / Industrial Relations, 14(4), 625-625. https://doi.org/10.7202/1022146ar

Tous droits réservés (C Département des relations industrielles de l’Université Laval, 1959
Ce document est protégé par la loi sur le droit d'auteur. L'utilisation des services d'Érudit (y compris la reproduction) est assujettie à sa politique d'utilisation que vous pouvez consulter en ligne.

https://apropos.erudit.org/fr/usagers/politique-dutilisation/ 
rés en aucune façon comme un revenu pour les travailleurs. Tandis que d'autres, comme les contributions pour un plan de pension, vont bénéficier aux travailleurs qui ne sont plus à l'emploi de l'entreprise. De plus, ce n'est que par accident que les auteurs ont touché à ces bénéfices que les travailleurs retirent soit du gouvernement ou de leurs propres contributions.

L'enquête a porté sur les industries suivantes: textile cotton, chaussure, radio, outillage, chantiers maritimes, acier, mines de charbon et chemins de fer. Et les pays couverts sont l'Autriche, la Belgique, le Danemark, la France, l'Allemagne de l'Ouest, la Grèce, l'Italie, la Turquie, le Royaume Uni et la You. goslavie.

L'ouvrage est divisé en quatre chapîtres. La procédure suivie dans l'enquête; les grandes catégories des items qui entrent dans le coût du travail selon les établissements; les items individuels du coût du travail selon les établissements, l'importance des salaires et des suppléments de salaire dans l'ensemble de l'économie.

On ne saurait trop souligner l'utilité d'études semblables.

G. D.

A History of American Labor, by Joseph G. Rayback, The MacMillan Company, New York 1959, BrettMacMillan Ltd., 132 Water Street South Galt, Ont. $\$ 6.00$

Voici un autre ouvrage qui s'ajoute à la littérature sur le mouvement ouvrier américain. En moins de cinq cents pages, l'auteur retrace les événements qui ont marqué la naissance, le développement, les luttes des syndicats ouvriers depuis la période coloniale jusqu'à l'enquête McClellan, et il essaie de les présenter dans leur contexte économique et politique.

Bien que l'auteur nous donne à la fin de son volume une bibliographie des principaux ouvrages dont il s'est servi, l'absence de notes et référenoes dans son texte nous empêche de contrôler ses sources et de vérifier ses allégations. $\mathrm{La}$ lecture en est rendue plus facile, mais elle ne peut satisfaire ceux qui recherchent la rigueur scientifique.

Ainsi, on aurait aimé pouvoir vérifier certaines affirmations qui ne cadrent point avec ce que l'on a l'habitude de soutenir. Par exemple, à la page 155 , d'un mot, l'auteur nous dit que Gompers n'a jamais été un socialiste.

Dans l'ensemble, c'est plutôt un ouvrage superficiel. Mais des lecteurs qui n'ont pas beaucoup de temps à disposer et qui veulent pourtant se familiariser avec l'histoire du syndicalisme aux Etats-Unis trouveront dans l'étude du Dr Rayback le livre qu'il leur faut.

$$
\text { G. D. }
$$

Conflict within the AFL, a study of craft versus industrial unionism, 19011938. By James O. Morris. Cornell University, Ithaca, New York, 1958. 319 pp. $\$ 5.00$

La scission qui s'est produite au sein de l'AFL par la création du CIO a été l'aboutissement d'une longue suite de divergences qui n'ont pu trouver de voies de compromis à l'intérieur de la grande centrale américaine et qui s'échelonnent de 1901 à 1935.

Etudier de près l'histoire de ces divergences, les analyser sous tous leurs angles est nécessaire si l'on veut connaître la dynamique qui caractérise le mouvement ouvrier américain. Non pas que l'histoire du mouvement ouvrier aux Etats-Unis se confonde avec celle de l'AFL, car même pendant cette période, à côté de cette centrale il a toujours existé d'autres groupements indépendants. Mais parce que l'on trouve au sein de l'AFL à la fois une tentative de grouper démocratiquement diverses tendances et aussi un échec.

Dans cet ouvrage, ainsi que l'indique le titre, l'auteur se borne à décrire et à interpréter le conflit qui a régné dans l'AFL pendant une période de trente ans. Ce conflit, s'il est surtout apparu comme celui d'une lutte entre deux formules d'organisations, les unions de métiers et les unions industrielles, était beaucoup plus profond. Au fond, c'était un conflit idéologique qui impliquait aussi une conception de l'or- 